\title{
N deposition affects allelopathic potential of Amaranthus retroflexus with different distribution regions
}

\author{
CONGYAN WANG ${ }^{1,2}$, JUN LIU ${ }^{1}$ and JIAWEI ZHOU ${ }^{1}$ \\ ${ }^{1}$ Institute of Environment and Ecology, Academy of Environmental Health and Ecological Security \& School \\ of the Environment and Safety Engineering, Jiangsu University, 212013, Zhenjiang, P.R. China \\ ${ }^{2}$ State Key Laboratory of Soil and Sustainable Agriculture, Institute of Soil Science, \\ Chinese Academy of Sciences, 210008, Nanjing, P.R. China
}

Manuscript received on August 3, 2016; accepted for publication on October 11, 2016

\begin{abstract}
This study aims to determine the allelopathic potential of Amaranthus retroflexus (Ar) with different climatic zones on seed germination and growth of $A$. tricolor $(A t)$ treated with a gradient $\mathrm{N}$ addition. $\mathrm{Ar}$ leaf extracts only displayed significantly allelopathic potential on the underground growth of $A r$ but not the aboveground growth of $A t$. The allelopathic potential of $A r$ leaf extracts on root length of $A t$ were enhanced under $\mathrm{N}$ addition and there may be a $\mathrm{N}$-concentration-dependent relationship. The effects of the extracts of $A r$ leaves that collected from Zhenjiang on seed germination and growth of $A t$ may be higher than that collected from Jinan especially on root length of At under medium $\mathrm{N}$ addition. This reason may be the contained higher concentration of secondary metabolites for the leaves of plants that growths in high latitudes compare with that growth in low latitudes. This phenomenon may also partly be attributed to the fact that $\mathrm{Ar}$ originated in America and/or south-eastern Asia which have higher similarity climate conditions as Zhenjiang rather than Jinan. The allelopathic potential of $A r$ on seed germination and growth of acceptor species may play an important role in its successful invasion especially in the distribution region with low latitudes.
\end{abstract}

Key words: Allelopathic potential, invasive plant, $\mathrm{N}$ deposition, seed germination, Amaranthus retroflexus.

\section{INTRODUCTION}

At present, biological invasion has triggered notable changes on the structure and functioning of native ecosystems (Gurevitch et al. 2011, Powell et al. 2013). Numerous studies have suggested that some plants can invade certain environments successfully via the released toxic compounds, a mechanism referred to as allelopathy (Callaway

Correspondence to: Congyan Wang

E-mail: liuyuexue623@163.com and Ridenour 2004, Yuan et al. 2013). Allelopathics compounds can pose a remarkably allelopathic effect on seed germination and growth of native species (Mlakar et al. 2012, Yuan et al. 2013, Wang et al. 2016a). Meanwhile, seed germination and growth are highly important for plant recruitment and resource competition (Turk and Tawaha 2003). Thus, the inhibition of seed germination and growth of native species mediated by the allelopathic effects of invasive species may obviously decrease the competitiveness of native species. 
Currently, one of the most significant global environmental problems has been an increase in atmospheric nitrogen $(\mathrm{N})$ deposition (Galloway et al. 2004, 2008). Meanwhile, the rapidly increased deposition of atmospheric $\mathrm{N}$ is expected to continue in the coming decades (Galloway et al. 2004, 2008, Liu et al. 2013). East Asia (mainly China) is currently one of the world's three largest areas of $\mathrm{N}$ deposition (Galloway et al. 2004, Wang et al. 2007, Liu et al. 2013). However, different regions in China may suffer different levels of atmospheric $\mathrm{N}$ deposition (Wang et al. 2007, Zhan et al. 2014). As the world's third largest country, meanwhile, China covers five climatic zones: cold-temperate, temperate, warm-temperate, subtropical, and tropical (Weber et al. 2008, Li et al. 2009). A wide range of habitats and environmental conditions allow China obviously vulnerable to the successful plantation of the invasive species that originating from diverse regions due to the potential invasive species from most areas of the world might searched out the suitable habitat somewhere in China eventually (Weber et al. 2008, Yan et al. 2014). Thus, the invasion of many invasive plants may cross multiple distribution regions (Yan et al. 2014). To illustrate, the notorious invasive plant Amaranthus retroflexus L. has been distributed in many regions of China (Weber et al. 2008, Yan et al. 2014). Thus, understanding the allelopathic potential of $A$. retroflexus $\mathrm{L}$. with different distribution regions on seed germination and growth of native species is important to elucidate the mechanism underlying its successful invasion especially under the condition with increasing amounts of anthropogenic $\mathrm{N}$ being deposited into ecosystems gradually.

The present study aims to determine the allelopathic potential of the invasive plant $A$. retroflexus with different distribution regions that belong to different climatic zones on seed germination and growth of acceptor species $A$. tricolor in the presence of a gradient of simulated
$\mathrm{N}$ deposition (control, $0 \mathrm{~g} \mathrm{~m}^{-2} \mathrm{yr}^{-1}$; low N, $2.5 \mathrm{~g} \mathrm{~m}^{-2}$ $\mathrm{yr}^{-1}$; medium N, $5 \mathrm{~g} \mathrm{~m}^{-2} \mathrm{yr}^{-1}$; and high $\mathrm{N}, 10 \mathrm{~g} \mathrm{~m}^{-2}$ $\mathrm{yr}^{-1}$ ). Both are members of the Amaranthus genus. A. retroflexus is a summer annual weed (Horak and Loughlin 2000) native to America (Mandák et al. 2011, Yang et al. 2011) and/or south-eastern Asia (Yang et al. 2011). At present, A. retroflexus is a common weed that grows vigorously in orchards, roadside verges, fields, woods, and scrubland in China and has been listed as a destructive and widespread invasive species in China (Yang et al. 2011). Allelopathy is invoked to explain the successful invasion of $A$. retroflexus (Mlakar et al. 2012, Konstantinović et al. 2014).

This study addressed the following hypotheses: (1) A. retroflexus exhibits allelopathic potential on seed germination and growth of $A$. tricolor; (2) the allelopathic potential of $A$. retroflexus on seed germination and growth of $A$. tricolor will be changed under exogenous $\mathrm{N}$ addition; and (3) there may be significant difference in the allelopathic potential of $A$. retroflexus between different distribution regions that belong to different climatic zones on seed germination and growth of $A$. tricolor.

\section{MATERIALS AND METHODS}

\section{EXPERIMENTAL DESIGN}

In September 2015, leaf samples of A. retroflexus were obtained from the following two distribution regions with different climatic zones in China: Jinan $\left(\mathrm{JN}, 36.68^{\circ} \mathrm{N}, 116.90^{\circ} \mathrm{E}\right.$, featuring a warm temperate climate), Zhenjiang $\left(\mathrm{ZJ}, 32.21^{\circ} \mathrm{N}\right.$, $119.52^{\circ} \mathrm{E}$, featuring a subtropical humid climate). The annual mean temperature of Jinan is approximately $13.8^{\circ} \mathrm{C}$, and monthly mean temperature reaches a maximum of $27.2^{\circ} \mathrm{C}$ in July and decreases to a minimum of $-3.2^{\circ} \mathrm{C}$ in January. The annual precipitation of Jinan is approximately $614 \mathrm{~mm}$, and monthly mean precipitation reaches a maximum of approximately $196 \mathrm{~mm}$ in July 
and decreases to a minimum of approximately $7 \mathrm{~mm}$ in January. The annual mean temperature of Zhenjiang is approximately $15.6{ }^{\circ} \mathrm{C}$, and its monthly mean temperature reaches a maximum of approximately $25^{\circ} \mathrm{C}$ in July and decreases to a minimum of approximately $-1{ }^{\circ} \mathrm{C}$ in January. The annual precipitation of Zhenjiang is approximately $1088 \mathrm{~mm}$, and monthly mean precipitation reaches a maximum of approximately $206 \mathrm{~mm}$ in July and decreases to a minimum of approximately $22 \mathrm{~mm}$ in December. The collected leaves of A. retroflexus were washed, air dried at room temperature for $48 \mathrm{~h}$, and then stored at $4^{\circ} \mathrm{C}$ for further study. $A$. tricolor seeds were chosen as the acceptor seeds and bought from a local vegetable market.

Approximately $10 \mathrm{~g}$ of air-dried leaves of $A$. retroflexus were placed in flasks containing $500 \mathrm{~mL}$ of distilled water and soaked for $48 \mathrm{~h}$ at room temperature. A. retroflexus leaf extracts were strained using a cheese cloth and then through two layers of filter paper to remove solid particles. The stock solution was stored at $4^{\circ} \mathrm{C}$ for further study. The concentrations of $A$. retroflexus leaf extracts from Jinan and Zhenjiang (abbreviated as $\mathrm{JN}$ and ZJ hereafter, respectively) were both set at $20 \mathrm{~g} \mathrm{~L}^{-1}$ with distilled water as control $\left(\mathrm{CK}, 0 \mathrm{~g} \mathrm{~L}^{-1}\right)$.

A mixed $\mathrm{N}$ solution was prepared with a 1:1:1 ratio of $\mathrm{KNO}_{3}-\mathrm{N}: \mathrm{NH}_{4} \mathrm{Cl}-\mathrm{N}$ : urea-N. The ratio of different $\mathrm{N}$ forms in the mixed $\mathrm{N}$ was similar to the global average ratio of natural atmospheric $\mathrm{N}$ deposition (Neff et al. 2002, Cornell et al. 2003). The concentrations were made with distilled water prior to use to create a series with gradient contents, namely, control $0 \mathrm{~g} \mathrm{~m}^{-2} \mathrm{yr}^{-1}$ (CK, fertilized with sterile distilled water only), low N, $2.5 \mathrm{~g} \mathrm{~m}^{-2} \mathrm{yr}^{-1}$ (N-2.5); medium N, $5 \mathrm{~g} \mathrm{~m}^{-2} \mathrm{yr}^{-1}$ (N-5); and high $\mathrm{N}, 10 \mathrm{~g} \mathrm{~m}^{-2} \mathrm{yr}^{-1}(\mathrm{~N}-10)$. N-5 corresponded to levels of $\mathrm{N}$ deposition already recorded in the Yangtze River Delta region of China (Wang et al. 2007). $\mathrm{N}-10$ represented a high deposition level that may be reached in the future.
The experiment included twelve treatments, each consisting of a combination of $\mathrm{N}$ form and aqueous extract regime. Five replicates were performed per treatment.

\section{SEED GERMINATION EXPERIMENT}

Experiments were performed through incubation in Petri dishes (Wang et al. 2016a). The $A$. tricolor seeds were surface sterilized $(1 \% \mathrm{NaClO}$ for approximately $15 \mathrm{~min}$ ) and then thoroughly washed thrice with deionized water. Thirty healthy seeds of $A$. tricolor were placed in a $9 \mathrm{~cm}$ Petri dish and covered with two layers of filter paper. The seeds were treated with deionized water, $\mathrm{N}$ solutions, and/or A.retroflexus leaf extracts. The Petri dishes were placed in a climate-controlled incubator at $25^{\circ} \mathrm{C}$ for $7 \mathrm{~d}$ with $12 \mathrm{~h}$ light per day (light intensity was set at $27.5 \mu \mathrm{mol} \cdot \mathrm{m}^{-2} \cdot \mathrm{s}^{-1}$ ). The number of germinated seeds was counted every day at incubation time, and each seed was considered to have germinated when its radicle protruded (Wang et al. 2016a).

\section{DATA MEASUREMENTS}

Ten seedlings per Petri dish were randomly selected for growth measurement on the same day. The plant height $(\mathrm{PH})$, root length (RL), seedling biomass (BM, fresh weight), germination rate (GR), germination potential (GP), germination index (GI), germination rate index (GRI) and vigor index (VI) of $A$. tricolor were determined. PH and RL were measured using a ruler (Wang et al. 2016a). BM was determined using an electronic balance with an accuracy of $0.001 \mathrm{~g}$ (Wang et al. 2016a). GR was calculated using the ratio of the final number of germinated seeds to the total number of seeds when no new germination occurred after $7 \mathrm{~d}$ of incubation (Wang et al. 2016a). GP was determined by dividing the number of germinated seeds on the third day by the total number of seeds (Wang et al. 2016a). GI was calculated using the following 
equation: $\mathrm{GI}=\sum G_{i} / I$, where $G_{i}$ represents the number of germinated seeds, and $I$ represents the time after cultivation (day) (Schmer et al. 2012). GRI was calculated using the following equation: GRI $=$ GR $\times$ GI (Steinmaus et al. 2000). VI was determined using the following equation: $\mathrm{VI}=\mathrm{BM}$ $\times$ GI (Lin et al. 2000).

\section{STATISTICAL ANALYSES}

Differences among various dependent variables were assessed using analysis of variance between groups followed by a multiple comparisons correction using the Student-Newman-Keuls test. All statistical analyses were performed using SPSS Statistics (version 22.0; IBM, Armonk, NY, USA). Statistical significance was set at $P$ values equal to or lower than 0.05 .

\section{RESULTS}

ALLELOPATHIC POTENTIAL OF A. RETROFLEXUS LEAF EXTRACTS ON SEED GERMINATION AND GROWTH OF A. TRICOLOR

A. retroflexus leaf extracts exerted significant effects on seed germination and growth of $A$. tricolor (Table I). In particular, the $\mathrm{PH}, \mathrm{BM}$, and VI of $A$. tricolor under $\mathrm{JN}$ and ZJ were significantly higher than those of $A$. tricolor under CK (Table I, $P<0.05)$. While, the RL of $A$. tricolor under JN and ZJ were significantly lower than those of $A$. tricolor under CK (Table I, $P<0.05$ ). Both $\mathrm{JN}$ and ZJ did not significantly affect the GR, GP, GI, and GRI of $A$. tricolor (Table I, $P>0.05$ ). There was no significant difference in seed germination and growth of $A$. tricolor between $\mathrm{JN}$ and ZJ (Table I, $P>0.05)$.

EFFECTS OF N ADDITION ON SEED GERMINATION AND GROWTH OF A. TRICOLOR

$\mathrm{N}$ addition remarkably affected seed germination and growth of $A$. tricolor (Table I). In particular, the $\mathrm{PH}, \mathrm{BM}$, and $\mathrm{VI}$ of $A$. tricolor under $\mathrm{N}$ addition were significantly higher than those of $A$. tricolor under CK (Table I, $P<0.05$ ). By contrast, the RL of A.tricolor decreased markedly with increasing concentrations of $\mathrm{N}$ addition (Table I, $P<0.05$ ). There was no significant difference in the GR, GP, GI, and GRI of $A$. tricolor between $\mathrm{N}$ addition and CK (Table I, $P>0.05$ ).

\section{ALLELOPATHIC POTENTIAL OF A. RETROFLEXUS LEAF EXTRACTS ON SEED GERMINATION AND GROWTH OF A. TRICOLOR UNDER N ADDITION}

The PH, BM, VI of $A$. tricolor under A. retroflexus leaf extracts and $\mathrm{N}$ addition, regardless of concentration, were significantly higher than those of $A$. tricolor under CK (Table I, $P<0.05$ ). Whereas, the RL of $A$. tricolor under $A$. retroflexus leaf extracts and $\mathrm{N}$ addition, regardless of concentration, was significantly lower than that of $A$. tricolor under CK (Table I, $P<0.05$ ). The GI of $A$. tricolor under $\mathrm{N}-10 * \mathrm{JN}$ was also significantly lower than that of $A$. tricolor under CK (Table I, $P<0.05$ ) but not the rest of the combined treatment of $A$. retroflexus leaf extracts and $\mathrm{N}$ addition (Table I, $P>0.05$ ). The combined treatment of $A$. retroflexus leaf extracts and $\mathrm{N}$ addition, regardless of concentration, did not pose significant effects on the GR, GP, and GRI of A. tricolor compared with CK (Table I, $P>0.05$ ).

The allelopathic potential of $A$. retroflexus leaf extracts on $A$. tricolor could be changed in the presence of different levels of $\mathrm{N}$ addition (Table I). In particular, RL of A. tricolor exposed to both of $\mathrm{JN}$ and $\mathrm{ZJ}$ with $\mathrm{N}$ addition, regardless of concentration, were significantly lower than those of $A$. tricolor exposed only to A. retroflexus leaf extracts (Table I, $P<0.05$ ). Meanwhile, the $\mathrm{RL}$ of $A$. tricolor under both $\mathrm{JN}$ and ZJ with $\mathrm{N}$ addition decreased significantly with increasing concentrations of $\mathrm{N}$ fertilizers (Table I, $P<0.05$ ). Moreover, the $\mathrm{PH}$ of $A$. tricolor under $\mathrm{N}-5^{*} \mathrm{ZJ}$ and $\mathrm{N}-10^{*} \mathrm{ZJ}$ was significantly higher than that of $A$. tricolor exposed only to the extracts of $A$. retroflexus leaves that collected from Zhenjiang (Table I, $P<$ 
TABLE I

Differences in the indices of $A$. tricolor with different treatments.

\begin{tabular}{|c|c|c|c|c|c|c|c|c|}
\hline Treatment & PH & RL & BM & GR & GP & GI & GRI & VI \\
\hline $\mathrm{CK}$ & $1.03 \pm 0.01 \mathrm{e}$ & $3.09 \pm 0.05 \mathrm{a}$ & $0.03 \pm 0.01 \mathrm{c}$ & $99.33 \pm 0.67 \mathrm{a}$ & $98.67 \pm 0.82 \mathrm{a}$ & $46.29 \pm 0.45 \mathrm{a}$ & $45.98 \pm 0.56 \mathrm{ab}$ & $1.17 \pm 0.25 \mathrm{c}$ \\
\hline $\mathrm{JN}$ & $1.73 \pm 0.05 \mathrm{~cd}$ & $2.42 \pm 0.06 b$ & $0.05 \pm 0.00 \mathrm{~b}$ & $99.33 \pm 0.67 \mathrm{a}$ & $98.67 \pm 0.82 \mathrm{a}$ & $45.92 \pm 0.35 \mathrm{ab}$ & $45.62 \pm 0.61 \mathrm{ab}$ & $2.44 \pm 0.16 b$ \\
\hline $\mathrm{ZJ}$ & $1.91 \pm 0.07 \mathrm{bc}$ & $2.65 \pm 0.11 b$ & $0.07 \pm 0.01 \mathrm{ab}$ & $99.33 \pm 0.67 \mathrm{a}$ & $98.00 \pm 0.82 \mathrm{a}$ & $46.53 \pm 0.42 \mathrm{a}$ & $46.23 \pm 0.69 \mathrm{ab}$ & $3.34 \pm 0.31 \mathrm{ab}$ \\
\hline $\mathrm{N}-2.5$ & $1.62 \pm 0.04 \mathrm{~d}$ & $2.52 \pm 0.08 b$ & $0.06 \pm 0.01 \mathrm{~b}$ & $98.67 \pm 0.82 \mathrm{a}$ & $98.00 \pm 0.82 \mathrm{a}$ & $45.70 \pm 0.51 \mathrm{ab}$ & $45.11 \pm 0.85 \mathrm{ab}$ & $2.58 \pm 0.28 b$ \\
\hline $\mathrm{N}-5$ & $1.76 \pm 0.03 \mathrm{~cd}$ & $2.14 \pm 0.09 \mathrm{c}$ & $0.05 \pm 0.01 \mathrm{~b}$ & $100.00 \pm 0.00 \mathrm{a}$ & $99.33 \pm 0.67 \mathrm{a}$ & $47.03 \pm 0.28 \mathrm{a}$ & $47.03 \pm 0.28 \mathrm{a}$ & $2.39 \pm 0.25 b$ \\
\hline $\mathrm{N}-10$ & $1.65 \pm 0.04 d$ & $1.64 \pm 0.03 \mathrm{~d}$ & $0.08 \pm 0.00 \mathrm{a}$ & $100.00 \pm 0.00 \mathrm{a}$ & $98.67 \pm 0.82 \mathrm{a}$ & $46.18 \pm 0.37 \mathrm{a}$ & $46.18 \pm 0.37 \mathrm{ab}$ & $3.64 \pm 0.21 \mathrm{a}$ \\
\hline $\mathrm{N}-2.5 * \mathrm{JN}$ & $1.77 \pm 0.03 \mathrm{~cd}$ & $1.71 \pm 0.06 \mathrm{~d}$ & $0.06 \pm 0.00 \mathrm{ab}$ & $100.00 \pm 0.00 \mathrm{a}$ & $99.33 \pm 0.67 \mathrm{a}$ & $45.40 \pm 0.85 \mathrm{ab}$ & $45.40 \pm 0.85 \mathrm{ab}$ & $2.80 \pm 0.22 \mathrm{ab}$ \\
\hline $\mathrm{N}-2.5 * \mathrm{ZJ}$ & $2.05 \pm 0.04 b$ & $1.78 \pm 0.11 \mathrm{~d}$ & $0.07 \pm 0.01 \mathrm{ab}$ & $100.00 \pm 0.00 \mathrm{a}$ & $100.00 \pm 0.00 \mathrm{a}$ & $46.72 \pm 0.17 \mathrm{a}$ & $46.72 \pm 0.17 \mathrm{a}$ & $3.41 \pm 0.25 \mathrm{ab}$ \\
\hline $\mathrm{N}-5 * \mathrm{JN}$ & $1.74 \pm 0.07 \mathrm{~cd}$ & $1.19 \pm 0.03 f$ & $0.06 \pm 0.00 \mathrm{ab}$ & $98.00 \pm 0.82 \mathrm{a}$ & $97.34 \pm 0.67 \mathrm{a}$ & $44.77 \pm 0.37 \mathrm{ab}$ & $43.88 \pm 0.61 \mathrm{ab}$ & $2.72 \pm 0.20 \mathrm{ab}$ \\
\hline $\mathrm{N}-5^{*} \mathrm{ZJ}$ & $2.36 \pm 0.07 \mathrm{a}$ & $1.41 \pm 0.04 \mathrm{e}$ & $0.07 \pm 0.00 \mathrm{ab}$ & $99.33 \pm 0.67 \mathrm{a}$ & $97.33 \pm 1.25 \mathrm{a}$ & $44.98 \pm 0.61 \mathrm{ab}$ & $44.69 \pm 0.74 \mathrm{ab}$ & $3.09 \pm 0.14 \mathrm{ab}$ \\
\hline $\mathrm{N}-10 * \mathrm{JN}$ & $1.82 \pm 0.02 \mathrm{~cd}$ & $0.67 \pm 0.05 \mathrm{~g}$ & $0.05 \pm 0.00 \mathrm{~b}$ & $99.33 \pm 0.67 \mathrm{a}$ & $98.67 \pm 0.82 \mathrm{a}$ & $43.72 \pm 0.48 b$ & $43.42 \pm 0.38 b$ & $2.35 \pm 0.18 b$ \\
\hline $\mathrm{N}-10 * \mathrm{ZJ}$ & $2.06 \pm 0.05 b$ & $0.79 \pm 0.04 \mathrm{~g}$ & $0.05 \pm 0.01 \mathrm{~b}$ & $98.67 \pm 0.82 \mathrm{a}$ & $98.00 \pm 0.82 \mathrm{a}$ & $45.00 \pm 0.83 \mathrm{ab}$ & $44.42 \pm 1.16 \mathrm{ab}$ & $2.43 \pm 0.28 b$ \\
\hline
\end{tabular}

Data with different letters in a vertical row indicate a significant difference $(P<0.05)$. Abbreviations: $\mathrm{PH}$, plant height $(\mathrm{cm})$; $\mathrm{RL}$, root length (cm); BM, seedling biomass (fresh weight) (g); GR, germination rate (\%); GP, germination potential (\%); GI, germination index; GRI, germination rate index; VI, vigor index; CK, sterile distilled water; JN, the extracts of $A$. retroflexus leaves that collected from Jinan, ZJ, the extracts of $A$. retroflexus leaves that collected from Zhenjiang; N-2.5, 2.5 g m-2 yr-1; N-5, $5 \mathrm{~g}$ m-2 $\mathrm{yr}-1 ; \mathrm{N}-10,10 \mathrm{~g} \mathrm{~m}-2 \mathrm{yr}-1 ; \mathrm{N}-2.5^{*} \mathrm{JN}$, the combined treatment of N-2.5 and JN; N-2.5*ZJ, the combined treatment of N-2.5 and ZJ; $\mathrm{N}-5^{*} \mathrm{JN}$, the combined treatment of $\mathrm{N}-5$ and $\mathrm{JN} ; \mathrm{N}-5 * \mathrm{ZJ}$, the combined treatment of N-5 and ZJ; N-10*JN, the combined treatment of N-10 and $\mathrm{JN} ; \mathrm{N}-10 * \mathrm{ZJ}$, the combined treatment of N-10 and ZJ.

0.05). In addition, under the addition of equal $\mathrm{N}$ concentration, the $\mathrm{PH}$ of $A$. tricolor under ZJ with was significantly higher than that under JN (Table I, $P<0.05)$. Furthermore, under the addition of medium N, the RL of $A$. tricolor under ZJ with was also significantly higher than that under JN (Table I, $P<0.05)$.

\section{DISCUSSION}

Some invaders can display pronounced allelopathic effects on the growth of native species in the invaded ecosystems to facilitate further invasion (Callaway and Ridenour 2004, Yuan et al. 2013, Wang et al. 2016a). As one of the most notorious invasive species in numerous agricultural areas, the allelopathic potential of $A$. retroflexus on the germination and growth of a wide-variety of field crops and vegetables are well documented (Mlakar et al. 2012, Konstantinović et al. 2014). This characteristic may play an important role during successful invasion of $A$. retroflexus. It is interesting that the extracts of $A$. retroflexus leaves that collected from both Jinan and Zhenjiang all exerted significantly negative effects on the root length of $A$. tricolor but triggered significantly positive effects on plant height, seedling biomass, and vigor index of $A$. tricolor. This implied that $A$. retroflexus leaf extracts only displayed significantly allelopathic potential on the underground growth of $A$. tricolor but not the aboveground growth of A. tricolor. The result was only partly consistent with the study's first hypothesis. The result may be attributed to the difference in the response of the underground and aboveground growth of $A$. tricolor to external effects mediated by $A$. retroflexus leaf 
extracts. Meanwhile, A. retroflexus leaf extracts increased the aboveground growth of $A$. tricolor may be attributed to the low concentration of allelochemicals released by $A$. retroflexus used in this study. Previous studies founded that allelopathic potential of $A$. retroflexus leaf extracts on the reduced germination and growth of crop seedlings is obviously dependent on its concentration (Mlakar et al. 2012). This finding may also be ascribed to the low concentration of allelopathic compounds released by invasive plants, which stimulated the reactive oxygen molecules in plant cell extension and then promoted growth of native species (Prithiviraj et al. 2007, Duke et al. 2006). Briefly, the low concentration of allelopathic compounds released by invasive species may exert weak stress on plant species; hence, native species adapted to this change and thereby there are stimulatory effects on the growth of native species triggered by the low concentration of allelopathic compounds of invasive plants (Hossain et al. 2016), namely hormesis effects (Viator et al. 2006, Takao et al. 2011). Thus, it is not surprising that $A$. retroflexus leaf extracts promoted the aboveground growth of A. tricolor in this study.

N plays an important role in the growth of plants, and enhanced nutrient levels in plant communities lead to increased plant productivity (Jin et al. 2016, Wang et al. 2016b). Meanwhile, exogenous $\mathrm{N}$ addition could stimulate seed germination and growth of plant species (Qiu and Zhang 2008). The results of this study showed that the increased levels of exogenous $\mathrm{N}$ addition obviously stimulated seed germination and growth of $A$. tricolor, especially the plant height, seedling biomass, and vigor index of A. tricolor significantly increased under $\mathrm{N}$ addition. The result was consistent with previous studies (Qiu and Zhang 2008). The enhanced seedling growth under exogenous $\mathrm{N}$ addition may be due to the elevated levels of soil available $\mathrm{N}$ (Bai et al. 2010, Zhang et al. 2013). Meanwhile, the root length of $A$. tricolor decreased significantly with increasing concentrations of exogenous $\mathrm{N}$ addition. This implied that exogenous $\mathrm{N}$ addition could inhibit the underground growth of $A$. tricolor. Thus, exogenous $\mathrm{N}$ addition promoted aboveground growth of $A$. tricolor but decreased its underground growth and thereby changed its biomass allocation pattern. The result was consistent with previous studies (Janssens et al. 2010, Wang et al. 2015).

The allelopathic potential of invasive species on seed germination and growth of native species may shift and change under the conditions with increased levels of $\mathrm{N}$ deposition. The results of this study showed that there may be a synergistic effect between exogenous $\mathrm{N}$ addition and $A$. retroflexus leaf extracts on the root length of A.tricolor, especially the root length of $A$. tricolor. Thus, the allelopathic potential of $A$. retroflexus leaf extracts on seed germination and growth of $A$. tricolor were enhanced under exogenous $\mathrm{N}$ addition and there may be a $\mathrm{N}$-concentration-dependent relationship. However, the combined treatment of the extracts of A. retroflexus leaves that collected from Zhenjiang and low as well as medium $\mathrm{N}$ treatment showed significant positive effects on the plant height of A. tricolor. The reason may be due the fact that exogenous $\mathrm{N}$ addition resulted in a shift in biomass allocation from underground to aboveground (Janssens et al. 2010, Wang et al. 2015). Consequently, the result was consistent with the study's second hypothesis. Meanwhile, the effects of the extracts of $A$. retroflexus leaves that collected from Zhenjiang on seed germination and growth of $A$. tricolor may be higher than that collected from Jinan especially on root length of $A$. tricolor under medium $\mathrm{N}$ addition. The reason could be a result of the contained higher concentration of secondary metabolites for the leaves of plants that growths in high latitudes compare with that growth in low latitudes (Wright et al. 2004). Gatti et al. (2014) also found that climate conditions can affect plant secondary metabolism (such as precipitation and temperature) and then alter the allelopathic 
activity of plant species via alter the production of allelochemicals. The result may also be attributed in part to the fact that $A$. retroflexus originated in America (Mandák et al. 2011, Yang et al. 2011) and/ or south-eastern Asia (Yang et al. 2011) which have higher similarity climate conditions as Zhenjiang rather than Jinan. The result was consistent with the study's third hypothesis. Thus, the allelopathic potential of $A$. retroflexus on seed germination and growth of native species may play an important role in its successful invasion especially in the distribution region with low latitudes.

\section{ACKNOWLEDGMENTS}

We are grateful for the funding provided by the National Natural Science Foundation of China (31300343) Open Science Research Fund of State Key Laboratory of State Key Laboratory of Soil and Sustainable Agriculture, China (Y20160023). We are very grateful to the anonymous reviewers for the insightful and constructive comments that greatly improved this manuscript.

\section{REFERENCES}

BAI YF, WU JG, CLARK CM, NAEEM S, PAN QM, HUANG JH, ZHANG LX AND HAN XG. 2010. Tradeoffs and thresholds in the effects of nitrogen addition on biodiversity and ecosystem functioning: evidence from inner Mongolia Grasslands. Global Chang Biol 16: 358-372.

CALLAWAY RM AND RIDENOUR WM. 2004. Novel weapons: invasive success and the evolution of increased competitive ability. Front Ecol Environ 2: 436-443.

CORNELL SE, JICKELLS TD, CAPE JN, ROWLAND AP AND DUCE RA. 2003. Organic nitrogen deposition on land and coastal environments: a review of methods and data. Atmos Environ 37: 2173-2191.

DUKE SO, CEDERGREEN N, VELINI ED AND BELZ RG. 2006. Hormesis: is it an important factor in herbicide use and allelopathy? Outlooks Pest Manage 17: 29-33.

GALLOWAY JN ET AL. 2004. Nitrogen cycles: past, present, and future. Biogeochemistry 70: 153-226.

GALLOWAY JN, TOWNSEND AR, ERISMAN JW, BEKUNDA M, CAI ZC, FRENEY JR, MARTINELLI LA, SEITZINGER SP AND SUTTON MA. 2008. Transformation of the nitrogen cycle: Recent trends, questions, and potential solutions. Science 320: 889-892.
GATTI AB, TAKAO LK, PEREIRA VC, FERREIRA AG, LIMA MIS AND GUALTIERI SCJ. 2014. Seasonality effect on the allelopathy of cerrado species. Braz J Biol 74: S064-S069.

GUREVITCH J, FOX GA, WARDLE GM, INDERJIT AND TAUB D. 2011. Emergent insights from the synthesis of conceptual frameworks for biological invasions. Ecol Lett 14: 407-418.

HORAK MJ AND LOUGHLIN TM. 2000. Growth analysis of four Amaranthus species. Weed Sci 48: 347-355.

HOSSAIN MK, ANWAR S AND NANDI R. 2016. Allelopathic effects of Mikania cordata on forest and agricultural crops in Bangladesh. J For Res 27: 155-159.

JANSSENS IA, DIELEMAN W, LUYSSAERT S, SUBKE JA, REICHSTEIN M, CEULEMANS R, CIAIS P, DOLMAN AJ, GRACE J AND MATTEUCCI G. 2010. Reduction of forest soil respiration in response to nitrogen deposition. Nature Geosci 3: 315-322.

JIN YH, XU JW, WANG YQ, WANG SX, CHEN ZS, HUANG XT AND NIU LJ. 2016. Effects of nitrogen deposition on tundra vegetation undergoing invasion by Deyeuxia angustifolia in Changbai Mountains. Chin Geogr Sci 26: 99-108.

KONSTANTINOVIĆ B, BLAGOJEVIĆ M, KONSTANTINOVIĆ B AND SAMARDŽIĆ N. 2014. Allelopathic effect of weed species Amaranthus retroflexus L. on maize seed germination. Rom Agric Res 31: 315321.

LI ET AL. 2009. Spartina alterniflora invasions in the Yangtze River estuary, China: An overview of current status and ecosystem effects. Ecol Eng 35: 511-520.

LIN WX, KIM KU AND SMIN DH. 2000. Rice allelopathic potential and its modes of action on barnyardgrass (Echinochloa crus-galli). Allelopathy J 7: 215-224.

LIU XJ ET AL. 2013. Enhanced nitrogen deposition over China. Nature 494: 459-462.

MANDÁK B, ZÁKRAVSKÝ P, DOSTÁL P AND PLAČKOVÁ I. 2011. Population genetic structure of the noxious weed Amaranthus retroflexus in Central Europe. Flora 206: 697-703.

MLAKAR SG, JAKOP M, BAVEC M AND BAVEC F. 2012. Allelopathic effects of Amaranthus retroflexus and Amaranthus cruentus extracts on germination of garden cress. Afr J Agr Res 7: 1492-1497.

NEFF JC, HOLLAND EA, DENTENER FJ, MCDOWELL WH AND RUSSELL KM. 2002. The origin, composition and rates of organic nitrogen deposition: A missing piece of the nitrogen cycle? Biogeochemistry 57: 99-136.

POWELL KI, CHASE JM AND KNIGHT TM. 2013. Invasive plants have scale-dependent effects on diversity by altering species-area relationships. Science 339: 316-318.

PRITHIVIRAJ B, PERRY LG, BADRI DV AND VIVANCO JM. 2007. Chemical facilitation and induced pathogen 
resistance mediated by a root-secreted phytotoxin. New Phytol 173: 852-860.

QIU XM AND ZHANG RZ. 2008. Influences of simulated acid rain on seed germination and seedling physiological characteristics in different colored cotton varieties. Cotton Sci 20: 23-28.

SCHMER MR, XUE Q AND HENDRICKSON JR. 2012. Salinity effects on perennial, warm-season (C4) grass germination adapted to the northern Great Plains. Can J Plant Sci 92: 873-881.

STEINMAUS SJ, TIMONTHY SP AND JODIE SH. 2000. Estimation of base temperature for nine weed species. $\mathrm{J}$ Exp Bot 51: 275-286.

TAKAO LK, RIBEIRO JPN AND LIMA MIS. 2011. Allelopathic effects of Ipomoea cairica (L.) Sweet on crop weeds. Acta Bot Bras 25: 858-864.

TURK MA AND TAWAHA AM. 2003. Allelopathic effect of black mustard (Brassica nigra L.) on germination and growth of wild oat (Avena fatua L.). Crop Prot 22: 673-677.

VIATOR RP, JOHNSON RM, GRIMM CC AND RICHARD EP. 2006. Allelopathic, autotoxic, and hormetic effects of postharvest sugarcane residue. Agron J 98: 1526-1531.

WANG CY, XIAO HG, ZHAO LL, LIU J, WANG L, ZHANG F, SHI YC AND DU DL. 2016a. The allelopathic effects of invasive plant Solidago canadensis on seed germination and growth of Lactuca sativa enhanced by different types of acid deposition. Ecotoxicology 25: 555-562.

WANG CY, XIAO HG, LIU J, ZHOU JW AND DU DL. 2016b. Insights into the effects of simulated nitrogen deposition on leaf functional traits of Rhus typhina. Pol J Environ Stud 25: 1279-1284.

WANG TJ, JIANG F, LI S AND LIU Q. 2007. Trends in air pollution during 1996-2003 and cross-border transport in city clusters over the Yangtze River Delta region of China. Terr Atmos Ocean Sci 18: 995-1009.

WANG Y, XI BY, BLOOMBERG M, MOLTCHANOVA E, LI GD AND JIA LM. 2015. Response of diameter growth, biomass allocation and $\mathrm{N}$ uptake to $\mathrm{N}$ fertigation in a triploid Populus tomentosa plantation in the North China Plain: Ontogenetic shift does not exclude plasticity. Eur J Forest Res 134: 889-898.

WEBER E, SUN SG AND LI B. 2008. Invasive alien plants in China: diversity and ecological insights. Biol Invasions 10: 1411-1429.

WRIGHT IJ ET AL. 2004. The worldwide leaf economics spectrum. Nature 428: 821-827.

YAN XL, LIU QR, SHOU HY, ZENG XF, ZHANG Y, CHEN L, LIU Y, MA HY, QI SY AND MA JS. 2014. The categorization and analysis on the geographic distribution patterns of Chinese alien invasive plants. Biodivers Sci 22: 667-676.

YANG Y, ZHAO WJ, LI ZH AND ZHU SF. 2011. Molecular identification of a 'Candidatus Phytoplasma ziziphi'related strain infecting Amaranth (Amaranthus retroflexus L.) in China. J Phytopathol 159: 635-637.

YUAN YG, WANG B, ZHANG SS, TANG JJ, TU C, HU SJ, YONG JWH AND CHEN X. 2013. Enhanced allelopathy and competitive ability of invasive plant Solidago canadensis in its introduced range. J Plant Ecol 6: 253-263.

ZHAN XY ET AL. 2014. Nitrogen deposition and its spatial pattern in main forest ecosystems along north-south transect of eastern China. Chinese Geogr Sci 24: 137-146.

ZHANG R, ZHOU ZC, LUO WJ, WANG Y AND FENG ZP. 2013. Effects of nitrogen deposition on growth and phosphate efficiency of Schima superba of different provenances grown in phosphorus-barren soil. Plant Soil 370: $435-445$. 